\title{
Fen Bilgisi Öğretmen Adaylarının Çoklu Zeka Alanları ile Öğrenme Biçim ve Stillerinin
}

\section{İncelenmesi: İlişkisel Bir Araştırma*}

\section{Yusuf ZORLU**, Fulya ZORLU***}

Öz: Bu araştırmada, fen bilgisi öğretmen adaylarının çoklu zeka alanları ile öğrenme biçim ve stilleri arasındaki ilişkilerin incelenmesi amaçlanmıştır. İlişkisel araştırma yöntemi kullanılmıştır. Araştırmaya; fen bilgisi öğretmenliği bölümünün ikinci sınıfında öğrenim gören 64 fen bilgisi öğretmen adayı katılmıştır. Araştırmada, Çoklu Zeka Envanteri (ÇKE) ile Öğrenme Stilleri Envanteri (ÖSE) veri toplama aracı olarak kullanılmıştır. Veriler, basit korelasyon ve tek yönlü varyans analizi (ANOVA) ile analiz edilmiştir. Fen bilgisi öğretmen adaylarının "Mantıksal” zeka alanı ile "Somut Yaşantı" öğrenme biçimi ve "Sosyal” zeka alanı ile "Yansitıcı Gözlem" öğrenme biçimi negatif, "Aktif Yaşantı" öğrenme biçimi ile "Mantıksal” ve "Sosyal” zeka alanları pozitif yönde ilişkilidir. "Değiştiren” öğrenme stiline sahip fen bilgisi öğretmen adaylarının "Mantıksal” zeka alanında daha düşük; "Sosyal” zeka alanında “Ayrıştıran” öğrenme stiline sahip fen bilgisi öğretmen adaylarının daha yüksek puan aldıkları tespit edilmiştir. Elde edilen sonuçlara göre çoklu zeka alanları ile öğrenme biçim ve stillerinin birbirleriyle ilişkilidirler. Bu bağlamda ileride, kaliteli bir eğitim için çoklu zeka alanları ile öğrenme biçim ve stilleri arasındaki ilişkilerin belirlenmesine yönelik yapılacak

\footnotetext{
* Bu araştırmanın bir kısmı 27. Uluslararası Eğitim Bilimleri Kongresinde sözlü bildiri olarak sunulmuştur.

** Dr. Öğr. Üyesi Dumlupınar Üniversitesi, Eğitim Fakültesi, Fen Bilgisi Eğitimi Anabilim Dalı, yusuf.zorlu@dpu.edu.tr https://orcid.org/0000-0002-4203-0908

*** Dr. Öğr. Üyesi Bülent Ecevit Üniversitesi, Ereğli Eğitim Fakültesi, Fen Bilgisi Eğitimi Anabilim Dalı, fulya.zorlu@dpu.edu.tr, https://orcid.org/0000-0001-8167-0839
}

\begin{tabular}{lll}
\hline Gönderim08.08.2018 Kabul:15.11.2018 & Yayın:15.03.2019
\end{tabular}


araştırmalar konuların öğretiminde dikkate alınacak özelliklerin belirlenmesinde yardımcı olacaktır.

Anahtar Kelimeler: Fen bilgisi eğitimi, Öğrenme biçim ve stilli, Çoklu zeka, Öğretmen eğitimi.

\title{
Investigation of Learning Orientations and Styles with Multiple Intelligence Areas of Preservice Elementary Science Teachers: A Correlational Research
}

\begin{abstract}
It was aimed in the study to examine the relationships between the learning styles and multiple intelligence areas of preservice elementary science teachers. Correlational method was used in the study. 64 preservice elementary science teachers who are sophomores were included in the research. In the study, Multiple Intelligences Inventory (MII) and Learning Styles Inventory (ESE) were used as data collection tools. The data were analyzed with simple correlation and one-way analysis of variance (ANOVA). It was determined that there is a negative relationship between the "Logical” intelligence area and "Concrete Experience" learning orientation, and "Interpersonal” intelligence area and "Reflective Observation" learning orientation, and a positive relationship between the "Logical" intelligence area and “Active Experimentation" learning orientation and "Interpersonal" intelligence area and “Active Experimentation” learning orientation of preservice elementary science teachers. It is seen that the points that preservice elementary science teachers who possess "Diverging" learning style in "Logical” intelligence area are lower than, and "Converging” learning style in "Interpersonal” intelligence area are higher than the preservice elementary science teachers who possess other learning styles. According to the results, multiple intelligence areas and learning orientations and styles are related to each other. In this context, future researches to determine the relationships between multiple intelligence areas with learning orientations and
\end{abstract}


styles for quality education will help in determining the characteristics to be considered in teaching subjects.

Keywords: Elementary science education, Learning orientation and style, Multiple intelligence, Teacher education.

\section{Giriş}

Günlük hayatta insanlar, karşılaştıkları sorunların çözümünde farklı yollar kullanırlar. Sorunların çözümünde kullanılan farklı yollar; bireylerin genel sorunları veya zorlukları çözme yeteneklerinin farklı olmasından kaynaklanmaktadır. Sorunların çözülmesi ise sorunların özelliğinden çok, bireysel yeteneklere bağlıdır ve bu yetenekler zekanın bileşenlerinden biri olarak görülür (Morgan, 1981). Gardner (1993)’e göre zeka, bireylerin yeteneklerini etkileyen farklı türlere sahiptir ve bunlar sekiz çeşit alana ayrılmıştır. Gardner'ın bu yaklaşımı Çoklu Zeka Kuramı olarak bilinir.

Çoklu Zeka Kuramındaki sekiz alan; "Sözel”, "Mantıksal”, “Görsel”, “Müziksel”, "Bedensel”, "Sosyal”, "İçsel” ve "Doğa” zeka alanı olarak sıralanabilir. Bireylerin, düşüncelerini başkalarının anlayabileceği şekilde ifade edebilme ve dili etkili kullanma yeteneği “Sözel (Dilsel) zeka alanı”, bir şeyin çalışma ilkelerini ortaya koyabilme ve nedensonuç ilişkisi kurarak analiz veya sentez yapabilme yeteneği “Mantıksal (Matematiksel) zeka alanı”, hayal gücünü kullanarak zihinde canlandırabilme ve görseller kullanarak duygu ve düşüncelerini ifade edebilme yeteneği “Görsel (Uzamsal) zeka alanı”, çevresel seslere karşı duyarlı olma, ritimleri algılama ve fark etme yeteneği "Müziksel (Ritmik) zeka alanı", hem bedeni hem de değişik eşyaları kullanarak duygu ve düşünceleri aktarabilme yeteneği “Bedensel (Kinestetik) zeka alanı”, diğer insanları anlama ve iletişim kurma yeteneği “Sosyal (Dışadönük) zeka alanı”, kendini tanıyarak çevresine uyum sağlama yeteneği “İçsel (Özedönük) zeka alanı”, doğaya ve doğal olaylara karşı ilgili olma yeteneği “Doğa (Natural) 
zeka alanı” ile ilgilidir (Gardner, 1993, 2003; Özden, 2014; Özdoğru-Şenel, 2016; Saban, 2005).

Çoklu Zeka Kuramı, her bireyde tüm zeka alanlarının mevcut olduğunu ve bu alanlardan birine ait becerinin daha fazla bulunduğunu savunmaktadır (Karatekin, Sönmez ve Kuş, 2010; Taşkın, 2017; Yağc1, 2006). Bu bağlamda kendisine özgü yetenekler bütünüyle karş1lıklı sorunlara etkin çözümler bulabilen ve çeşitli alanlarda toplumda değer gören ürünler/çıktılar ortaya koyabilen bireyler zeki olarak nitelendirilebilir (Gürel ve Tat, 2010). Toplumsal koşullarla veya ihtiyaçlarla ilişkili olarak, bireylerin baskın zeka alanları değişimler gösterebilir (Çalışandemir, 2010). Çünkü değişen şartlara uyum, farklı düşünme biçimleri ile ilgilidir ve zeka alanları bireylerin düşünme biçimleri tarafından şekillenmektedir (Gardner, 2010). Düşünme biçimlerinin önem kazandığı öğrenme sürecinde öğrenenler, kendi zeka alanlarında tam potansiyellerini yakalayabilecekleri farklı öğrenme yollarını tercih edebilirler. Öğrenme ortamlarında farklı düşünme biçimlerinin varlığı, farklı öğrenme biçim ve stillerinin oluşmasını da sağlamıştır. Çünkü öğrenme biçim ve stilleri; öğrenenlerin öğrenme ortamını nasıl algıladıkları, etkileşim kurdukları ve yanıt verdikleri ile ilgili bilişsel, duyuşsal ve fizyolojik özelliklerdir (Keefe, 1982). Özellikleri doğrultusunda öğrenme biçim ve stilleri esnek bir yapıya sahiptir ve bilim insanları tarafından farklı kategorilere ayrılmıştır (Hunt, 1987; Gardner, 2006; Kolb ve Kolb; 2005).

Eğitim alanlarında öğretme ve öğrenme uygulamalarını etkileyen farklı öğrenme biçim ve stilleri bulunmaktadır (Curry, 1990). Kolb’a göre hissederek öğrenen “Somut Yaşantı”, izleyerek öğrenen "Yansıtıcı Gözlem”, düşünerek öğrenen “Soyut Kavramsallaştırma” ve yaparak öğrenen “Aktif Yaşantı” olmak üzere dört farklı öğrenme biçimi vardır. Öğrenme biçimlerinden yola çıkılarak öğrenme stillerinin kapsamı belirlenir. Bunlar; "Somut Yaşantı” 
ve “Aktif Yaşantı" öğrenme biçimlerini kapsayan "Yerleştiren” öğrenme stili, "Somut Yaşantı” ve “Yansıtıcı Gözlem” öğrenme biçimlerini kapsayan “Değiştiren” öğrenme stili, “Soyut Kavramsallaştırma” ve "Yansıtıcı Gözlem” öğrenme biçimlerini kapsayan “Özümseyen” öğrenme stili, “Soyut Kavramsallaştırma” ve “Aktif Yaşantı” öğrenme biçimlerini kapsayan “Ayrıştıran” öğrenme stilidir (Aşkar ve Akkoyunlu, 1993; Kolb, 1985; Kolb ve Kolb, 2005).

Gardner'ın sekiz zeka alanı ile Kolb’un dört öğrenme biçim ve stilleri arasında bir benzerlik olduğu; ama tamamen aynı olmadığı düşünülmektedir (Zull, 2002). Denig (2004) ve Gardner (2003) çoklu zeka alanları ile öğrenme biçim ve stillerinin aynı şey olmadığını yani birbirinden farklı olduğunu ifade etmiştir. Öğrenme biçim ve stilleri doğuştan gelen karakteristik bir özelliktir ve değiştirilmesi oldukça zordur; fakat bireyde bir zeka alanına ait beceriler diğer zeka alanlarına ait becerilere göre daha fazla olabilmekte ve bu durum zamanla değişebilmektedir (Boydak, 2001; Gardner, 2003). Gardner (2003) öğrenme biçim ve stilleri ile çoklu zeka alanları arasındaki ilişkinin incelenmesi gerektiğini ifade etmiştir. Alanyazın incelediğinde çoklu zeka alanları ile öğrenme biçim ve stilleri arasındaki ilişkiyi inceleyen çalışmaların sınırlı sayıda olduğu görülmektedir (Aygül, 2015; Chambel ve Guimarães, 2005; Demir ve Aybek, 2014; Klein, 2003; Silver, Strong ve Perini, 2000). Çoklu zeka alanları ile öğrenme biçim ve stillerindeki ilişkilerin incelenmesi,

1. Öğrenme biçim ve stillerinin doğuştan gelen karakteristik bir özellik olduğu ve değişmesinin zor olacağı düşünüldüğünde öğrenme biçim ve stillerini geliştirmek için çoklu zeka alanlarını dikkate alan uygulamalarda kullanılabilirliği

2. Çoklu zeka alanlarını geliştirmek için öğrencilerin öğrenme biçim ve stillerine göre uygulamaların yapılabilirliği 
düşünüldügüünde oldukça önem arz etmektedir. Eğitimin amaçlarından biri de bireyin ve toplumun ihtiyaçlarını karşılamaktır. Bireyin ilgi alanlarına, öğrenme biçim ve stillerine yönelik eksiklerin giderilmesi açısından çoklu zeka alanları ile öğrenme biçim ve stilleri arasındaki ilişkilerin bilinmesi ve ilişkilere göre uygulamaların yapılması bu alandaki ihtiyaçların giderilmesinde yardımcı olabilir. Ayrıca ilgili alanyazında, fen bilimleri alanında lisans düzeyinde gerçekleştirilen bir çalışmaya rastlanmamıştır. Etkili bilimsel çalışmalar yürütüp buna bağlı olarak yeni teknolojik araçlar üreten ülkeler arasında yer almak fen eğitiminin kalitesini artırmakla mümkün olabilir. Kaliteli fen eğitiminin olabilmesi için fen bilgisi öğretmen adaylarının eğitimine önem verilmelidir. Bu doğrultuda araştırmada, fen bilgisi öğretmen adaylarının çoklu zeka alanları ile öğrenme biçim ve stilleri arasındaki ilişkilerin incelenmesi amaçlanmıştır. Bu amaç doğrultusunda aşağıdaki araştırma sorusuna yanıt aranmaya çalışılmıştır.

\section{Araştırmanın Problemi}

Fen bilgisi öğretmenliği bölümünün ikinci sınıfında öğrenim gören öğretmen adaylarının çoklu zeka alanları ile öğrenme biçim ve stilleri arasında ilişki var mıdır?

\section{Alt sorular}

Fen bilgisi öğretmenliği bölümünün ikinci sınıfında öğrenim gören öğretmen adaylarının;

1. Çoklu zeka alanlarının seviyeleri nelerdir?

2. Öğrenme biçim ve stilleri nelerdir?

3. Çoklu zeka alanları ile öğrenme biçimleri arasında ilişki var mıdır?

4. Çoklu zeka alanlarından elde edilen puanlarda öğrenme stillerine göre istatistiksel olarak anlamlı fark var mıdır? 


\section{Yöntem}

Araştırmada ilişkisel (correlational) araştırma yöntemi kullanılmıştır. İlişkisel araştırma yöntemi; iki veya daha fazla sayıda değişkenlerin arasında karşılaştırma yolu ile elde edilen ilişkileri belirlemek için yapılan araştırma yöntemidir (Karasar, 2016). Bu yöntem ile fen bilgisi öğretmen adaylarının çoklu zeka alanları ile öğrenme biçim ve stilleri arasındaki ilişkiler incelenmiştir.

\section{Katılımcılar}

Araştırmaya; bir devlet üniversitesinin eğitim fakültesinin Fen Bilgisi öğretmenliği bölümünün ikinci sınıfında öğrenim gören 64 Fen Bilgisi öğretmen adayı katılmıştır. Fen bilgisi öğretmen adaylarının cinsiyetleri 36 (\% 56.4) kız ve 28 (\% 43.6) erkek olarak dağılım göstermektedir.

\section{Veri Toplama Araçları}

Çoklu zeka envanteri (ÇZE). Çoklu Zeka Envanteri (ÇZE), Özden (1997) tarafından Türkçeye uyarlanmıştır. ÇZE; maddeleri birden beşe kadar derecelendirilmiş likert tipli envanterdir. ÇZE’nin güvenirlik katsayısı 0.92 olarak hesaplanmıştır. ÇZE; “Sözel”, "Mantıksal”, “Görsel”, “Müziksel”, "Bedensel”, "Sosyal”, “İçsel” ve "Doğa” olmak üzere sekiz zeka alanından oluşmaktadır. ÇZE, her bir zeka alanına ait 10 soru içermektedir. Her bir zeka alanı 10-50 puan aralığında puan almaktadır. Puan aralığının değerlendirilmesi: 10-17 puan “Gelişmemiş”, 18-25 puan “Az Gelişmiş”, 26-33 puan “Orta Düzey Gelişmiş”, 34-41 puan "Gelişmiş" ve 42-50 puan "Çok Gelişmiş" şeklinde yapılmaktadır (Aktaran Özden, 2014). Bu araştırmadaki örnekleme uygulanan ÇZE’nin güvenirlik katsayısı 0.91 olarak hesaplanmıştır. Ölçeklerin 0.60 ve üzeri güvenirlik katsayısına sahip olması güvenilir olduğunu gösterir (Pallant, 2003). 
Kolb öğrenme stilleri envanteri (ÖSE). Öğrenme Stilleri Envanteri (ÖSE), Kolb (1984) tarafından geliştirilmiş ve Aşkar ve Akkoyunlu (1993) tarafından Türkçeye uyarlanmıştır. ÖSE’nin güvenirlik katsayıları "Somut Yaşantı” için 0.58, "Yansıtıcı Gözlem” için 0.70, "Soyut Kavramsallaştırma" için 0.71 ve "Aktif Yaşantı" için 0.65 olarak hesaplanmıştır. ÖSE’nde 12 madde ve her maddeye ait dört seçenek yer almaktadır. Her bir maddeye ait seçenekler 4'ten 1'e doğru sıralanarak doldurulmaktadır. ÖSE’nde, dört seçenek işaretlemesine göre "Somut Yaşantı", "Yansıtıcı Gözlem”, “Soyut Kavramsallaştırma” ve “Aktif Yaşantı” öğrenme biçimleri 12-48 arasında puanlama oluşmaktadır. "Soyut Kavramsallaştırma” öğrenme biçiminden “Somut Yaşantı” öğrenme biçiminin farkı (Yatay Eksen) ve “Aktif Yaşantı” öğrenme biçiminden "Yansıtıcı Gözlem” öğrenme biçiminin fark1 (Düşey Eksen) ile diyagram oluşturulur. Her bir fen bilgisi öğretmen adayının yatay ve düşey eksen puanları hesaplanarak diyagram yardımıyla öğrenme stili belirlenir. Diagramdan belirlenen öğrenme stilleri; "Değiştiren”, “Özümseyen”, “Ayrıştıran” ve "Yerleştiren” öğrenme stilleridir. Bu araştırmadaki örnekleme uygulanan ÖSE'nin güvenirlik katsayıları “Somut Yaşantı" için 0.57, "Yansıtıcı Gözlem” için 0.68, “Soyut Kavramsallaştırma” için 0.70 ve “Aktif Yaşantı” için 0.61 olarak hesaplanmıştır. Ölçeklerin 0.60 ve üzeri güvenirlik katsayısına sahip olması güvenilir olduğunu gösterir (Pallant, 2003).

\section{Veri Analizi}

Araştırmadan elde edilen veriler betimsel ve kestirimsel istatistik analiz yaklaşımları dikkate alınarak SPSS paket programıyla analiz edilmiştir (URL-1). Betimsel istatistik analizinde elde edilen veriler aritmetik ortalama, en yüksek puan, en düşük puan ve frekans olarak verilmiştir. Kestirimsel istatistik analizinde basit korelasyon ve tek yönlü varyans analizi (ANOVA) yapılmıştır. 
YYÜ Eğitim Fakültesi Dergisi (YYU Journal of Education Faculty), 2019; 16(1):49-78, http://efdergi.yyu.edu.tr

Tablo 1. Kolomogorov-Smirnov analizi sonuçları

\begin{tabular}{llrrr}
\hline Envanter & & \multicolumn{3}{c}{ Kolmogorov-Smirnov $^{\mathrm{a}}$} \\
& Sözel & İstatistik & sd & $\mathrm{p}$ \\
\hline ÇZE & Mantıksal & 0.083 & 64 & $0.200^{*}$ \\
& Görsel & 0.092 & 64 & $0.200^{*}$ \\
& Müziksel & 0.108 & 64 & 0.060 \\
& Bedensel & 0.110 & 64 & 0.056 \\
& Sosyal & 0.090 & 64 & $0.200^{*}$ \\
& İssel & 0.082 & 64 & $0.200^{*}$ \\
& Doğa & 0.085 & 64 & $0.200^{*}$ \\
& Somut Yaşantı & 0.067 & 64 & $0.200^{*}$ \\
\hline ÖSE & Yansitıcı Gözlem & 0.110 & 64 & 0.056 \\
& Soyut Kavramsallaştırma & 0.090 & 64 & $0.200^{*}$ \\
& Aktif Yaşantı & 0.109 & 64 & 0.057 \\
& & 0.106 & 64 & 0.053 \\
\hline
\end{tabular}

Verilerin parametrik dağılıp dağılmadığına bakmak için veri sayısı 50'den fazla ise Kolmogorov-Smirnov analizi yapılmalıdır (Büyüköztürk, 2010). Bu doğrultuda çalışmanın verilerine Kolmogorov-Smirnov analizi yapılmış ve elde edilen sonuçlar incelediğinde verilerin dağılımının parametrik olduğu belirlenmiştir (Tablo 1). 


\section{Bulgular}

Fen bilgisi öğretmen adaylarının ÇKE’nde yer alan zeka alanlarından aldıkları puanların betimsel istatistik değerleri Tablo 1'de verilmiştir. dăgllımı

Tablo 2. Fen bilgisi öğretmen adaylarının çoklu zeka alanlarından aldıkları puanların

\begin{tabular}{lrrrr}
\hline Zeka Türü & En Düşük & En Yüksek & Ortalama & Düzey \\
\hline Sözel & 20 & 44 & 33.64 & Gelişmiş \\
Mantıksal & 22 & 49 & 38.36 & Gelişmiş \\
Görsel & 20 & 50 & 37.13 & Gelişmiş \\
Müziksel & 14 & 49 & 34.09 & Gelişmiş \\
Bedensel & 20 & 47 & 37.22 & Gelişmiş \\
Sosyal & 15 & 48 & 36.02 & Gelişmiş \\
İçsel & 24 & 47 & 35.64 & Gelişmiş \\
Doğa & 20 & 50 & 36.31 & Gelişmiş \\
\hline
\end{tabular}

Tablo 2 incelediğinde fen bilgisi öğretmen adaylarının genel olarak bütün zeka alanlarında 33.64-38.36 arasında puanlar aldıkları tespit edilmiştir. Fen bilgisi öğretmen adaylarının her bir zeka alanından aldıkları puanların aritmetik ortalamalarına göre zeka alanlarının gelişmiş düzeyde olduğu belirlenmiştir. Ayrıca fen bilgisi öğretmen adaylarının en yüksek puan ortalamasının Mantıksal zeka alanında ve en düşük puan ortalamasının Sözel zeka alanında olduğu belirlenmiştir.

Fen bilgisi öğretmen adaylarının ÖSE’nde yer alan öğrenme biçimlerinden aldıkları puanların betimsel istatistik değerleri Tablo 3'de verilmiştir.

Tablo 3. Fen bilgisi ögrretmen adaylarının öğrenme biçimlerinden aldıkları puanların dă̆llımı

\begin{tabular}{lrrr}
\hline Öğrenme Biçimleri & En Düşük & En Yüksek & Ortalama \\
\hline Somut Yaşantı (Hissederek) & 17 & 37 & 27.89 \\
Yansıtıcı Gözlem (İzleyerek) & 21 & 34 & 27.45 \\
Soyut Kavramsallaştırma (Düşünerek) & 21 & 40 & 32.16 \\
Aktif Yaşantı (Yaparak) & 20 & 41 & 32.48 \\
\hline
\end{tabular}

Tablo 3 incelediğinde “Soyut Kavramsallaştırma (Düşünerek)” ve “Aktif Yaşantı (Yaparak)" öğrenme biçimlerinde diğer öğrenme biçimlerine göre daha yüksek puan 
ortalamasının olduğu görülmektedir. Fen bilgisi öğretmen adaylarının "Somut Yaşantı (Hissederek)" ve "Yansıtıcı Gözlem (İzleyerek)” öğrenme biçimlerinde aldıkları puan ortalamalarının birbirine yakın olduğu görülmektedir.
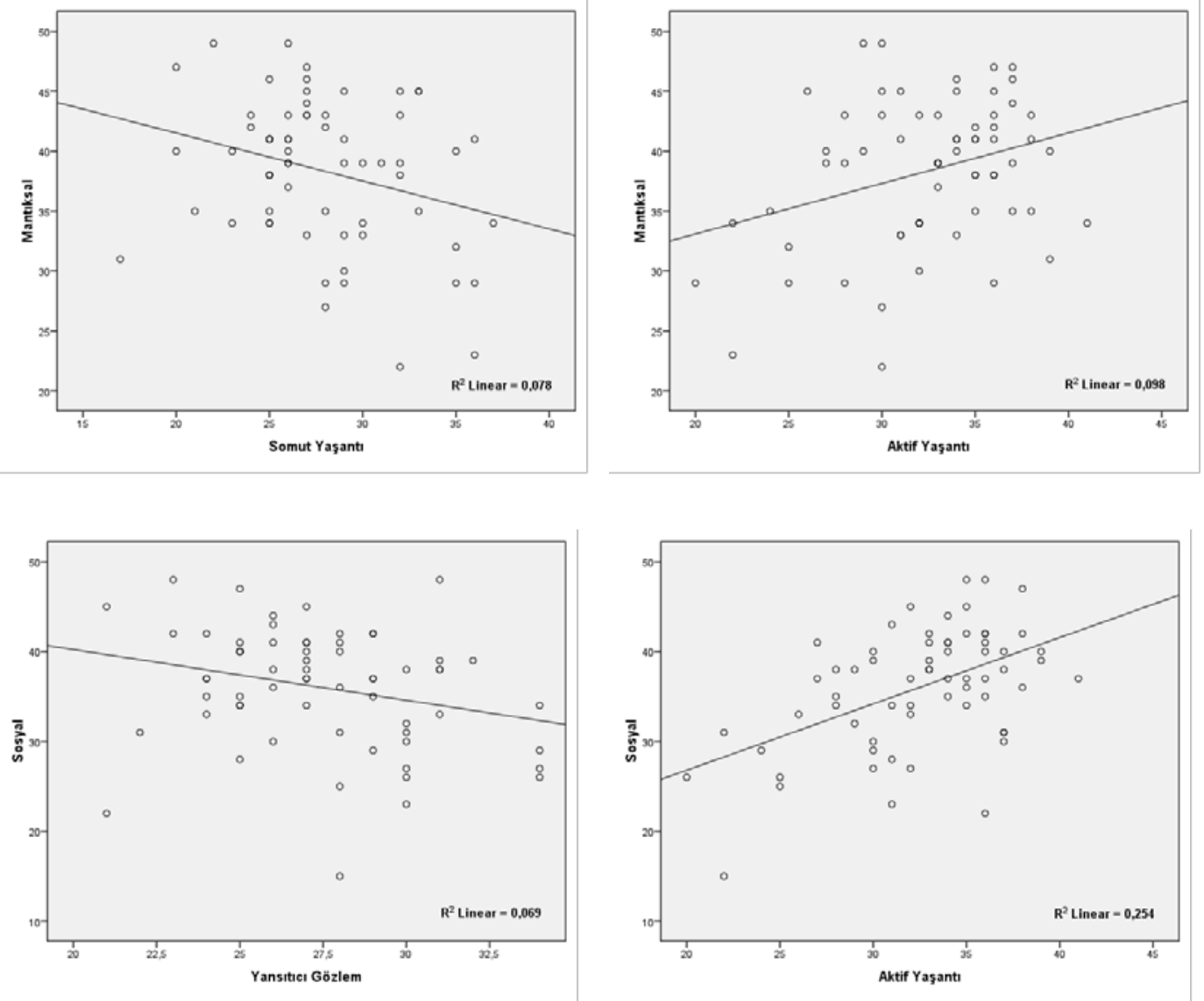

Şekil 1. ÇZE ile ÖSE’nden alınan puanların saçılma grafikleri

Öğrencilerin çoklu zeka alanları ile öğrenme biçimleri arasındaki ilişkileri incelemek için basit korelasyon analizi yapılmıştır. Fen bilgisi öğretmen adaylarının "Mantıksal" zeka alanı ile "Somut Yaşantı" öğrenme biçimi ve "Sosyal” zeka alanı ile "Yansıtıcı Gözlem" öğrenme biçimi arasında negatif yönde ve anlamlı düzeyde bir ilişki olduğu tespit edilmiştir (Mantıksal Zeka ile Somut Yaşantı: Pearson's r=-0.280; $\mathrm{p}<0.05$. Sosyal Zeka ile Yansitıcı Gözlem: Pearson's r=-0.262; $<<0.05$ ) (Şekil 1). Fen bilgisi öğretmen adaylarının "Mantıksal” zeka alanı ile "Aktif Yaşantı" öğrenme biçimi ve "Sosyal” zeka alanı ile "Aktif Yaşantı" 
öğrenme biçimi arasında pozitif yönde ve anlamlı düzeyde bir ilişki olduğu tespit edilmiştir (Mantıksal Zeka ile Aktif Yaşantı: Pearson's r=0.313; $\mathrm{p}<0.05$. Sosyal Zeka ile Aktif Yaşantı: Pearson's r=0.504; $\mathrm{p}<0.05$ ) (Şekil 1). Şekil 1 incelendiğinde; Pearson's korelasyon katsayısına göre "Mantıksal” zeka alanı ile "Aktif Yaşantı" öğrenme biçimi ve "Sosyal” zeka alanı ile “Aktif Yaşantı” öğrenme biçimi arasında orta düzeyde; "Mantıksal” zeka alanı ile "Somut Yaşantı" öğrenme biçimi ve "Sosyal" zeka alanı ile "Yansıtıcı Gözlem" öğrenme biçimi arasında düşük düzeyde bir ilişki olduğu belirlenmiştir. Ayrıca; diğer çoklu zeka alanları ile öğrenme biçimleri arasında istatistiksel olarak anlamlı bir ilişki olmadığı tespit edilmiştir $(\mathrm{p}>0.05)$.

Fen bilgisi öğretmen adaylarının ÖSE’nde yer alan öğrenme stillerine göre dağılımları Tablo 4'te verilmiştir.

Tablo 4. Fen bilgisi öğretmen adaylarının öğrenme stillerine göre dă̆llımları

\begin{tabular}{lrr}
\hline Öğrenme Stilleri & Frekans & Yüzde (\%) \\
\hline Yerleștiren & 6 & 9.4 \\
Değiştiren & 18 & 28.1 \\
Özümseyen & 19 & 29.7 \\
Ayriştıran & 21 & 32.8 \\
Toplam & 64 & 100 \\
\hline
\end{tabular}

Tablo 4 incelediğinde fen bilgisi öğretmen adaylarının yaklaşı \%9.4'ünün "Yerleştiren” öğrenme stiline, yaklaşık \%32.8'inin ise “Ayrıştıran” öğrenme stiline sahip oldukları görülmektedir. Birbirine yakın sayıda "Değiştiren” ve “Özümseyen” öğrenme stillerinde oldukları belirlenmiştir.

Farklı öğrenme stillerine sahip öğretmen adaylarının çoklu zeka alanlarındaki puanları arasındaki farkı istatistiksel olarak incelemek için ANOVA analizi yapılmış ve sonuçlar Tablo 5’te verilmiştir. 
Tablo 5. Çoklu zeka alanlarının öğrenme stillerine göre ANOVA analizi sonuçları

\begin{tabular}{llrrrrr}
\hline $\begin{array}{l}\text { Zeka } \\
\text { Alanları }\end{array}$ & Gruplar & $\begin{array}{r}\text { Karelerin } \\
\text { Toplamı }\end{array}$ & SD & $\begin{array}{r}\text { Karelerin } \\
\text { Ortalaması }\end{array}$ & F & $\mathrm{p}$ \\
\hline Sözel & Gruplar arası & 79.227 & 3 & 26.409 & 1.101 & 0.356 \\
& Grup içi & 1439.507 & 60 & 23.992 & & \\
& Toplam & 1518.734 & 63 & & & \\
\hline Mantıksal & Gruplar arası & $\mathbf{3 9 8 . 3 1 1}$ & $\mathbf{3}$ & $\mathbf{1 3 2 . 7 7 0}$ & $\mathbf{4 . 1 0 5}$ & $\mathbf{0 . 0 1 0}$ \\
& Grup içi & $\mathbf{1 9 4 0 . 4 2 3}$ & $\mathbf{6 0}$ & $\mathbf{3 2 . 3 4 0}$ & & \\
& Toplam & $\mathbf{2 3 3 8 . 7 3 4}$ & $\mathbf{6 3}$ & & & \\
\hline Görsel & Gruplar arası & 215.489 & 3 & 71.830 & 2.134 & 0.105 \\
& Grup içi & 2019.511 & 60 & 33.659 & & \\
& Toplam & 2235.000 & 63 & & & \\
\hline Müziksel & Gruplar arasi & 53.935 & 3 & 17.978 & 0.233 & 0.873 \\
& Grup içi & 4625.502 & 60 & 77.092 & & \\
& Toplam & 4679.438 & 63 & & & \\
\hline Bedensel & Gruplar arasi & 82.483 & 3 & 27.494 & 0.905 & 0.444 \\
& Grup içi & 1822.454 & 60 & 30.374 & & \\
& Toplam & 1904.938 & 63 & & & \\
\hline Sosyal & Gruplar arası & $\mathbf{6 4 1 . 3 3 9}$ & $\mathbf{3}$ & $\mathbf{2 1 3 . 7 8 0}$ & $\mathbf{6 . 0 1 7}$ & $\mathbf{0 . 0 0 1}$ \\
& Grup içi & $\mathbf{2 1 3 1 . 6 4 5}$ & $\mathbf{6 0}$ & $\mathbf{3 5 . 5 2 7}$ & & \\
& Toplam & $\mathbf{2 7 7 2 . 9 8 4}$ & $\mathbf{6 3}$ & & & \\
\hline Içsel & Gruplar arası & 168.317 & 3 & 56.106 & 2.203 & 0.097 \\
& Grup içi & 1528.417 & 60 & 25.474 & & \\
& Toplam & 1696.734 & 63 & & & \\
\hline Doğa & Gruplar arasi & 186.813 & 3 & 62.271 & 1.610 & 0.197 \\
& Grup içi & 2320.937 & 60 & 38.682 & & \\
& Toplam & 2507.750 & 63 & & & \\
\hline
\end{tabular}

Tablo 5 incelediğinde öğretmen adaylarının öğrenme stillerine göre "Mantıksal” ve "Sosyal” zeka alanlarında istatistiksel olarak anlamlı farklılıklar olduğu belirlenmiştir [Mantıksal Zeka Alanı: $F_{(3,63)}=4.105 ; p=0.010$. Sosyal Zeka Alanı: $\left.F_{(3,63)}=6.017 ; p=0.001\right]$. Diğer zeka alanlarında öğrenme stillerine göre istatistiksel olarak anlamlı bir farklılık tespit edilmemiştir ( $>0.05)$. "Mantıksal" ve "Sosyal" zeka alanlarındaki anlamlı farkın hangi öğrenme stillerinde olduğu anlamak için LSD analizi yapılmıştır (Tablo 6). 
Tablo 6. "Mantıksal” ve "Sosyal" zeka alanlarının ögrrenme stillerine göre çoklu karşılaştırma sonuçları (LSD)

\begin{tabular}{|c|c|c|c|c|c|}
\hline Zeka Alanı & (I)gruplar & (J)gruplar & Ortalama fark (I-J) & Standart hata & $\mathrm{p}$ \\
\hline \multirow[t]{12}{*}{ Mantıksal } & Yerleştiren & Ayrıştıran & 2.619 & 2.633 & 0.324 \\
\hline & & Değiştiren & $7.722^{*}$ & 2.681 & 0.005 \\
\hline & & Özümseyen & 3.175 & 2.663 & 0.238 \\
\hline & Ayriştıran & Yerleştiren & -2.619 & 2.633 & 0.324 \\
\hline & & Değiştiren & $5.103^{*}$ & 1.827 & 0.007 \\
\hline & & Özümseyen & 0.556 & 1.801 & 0.758 \\
\hline & Değiştiren & Yerleştiren & $-7.722^{*}$ & 2.681 & 0.005 \\
\hline & & Ayrıştıran & $-5.103^{*}$ & 1.827 & 0.007 \\
\hline & & Özümseyen & $-4.547^{*}$ & 1.871 & 0.018 \\
\hline & Özümseyen & Yerleştiren & -3.175 & 2.663 & 0.238 \\
\hline & & Ayriştıran & -0.556 & 1.801 & 0.758 \\
\hline & & Değiştiren & $4.547^{*}$ & 1.871 & 0.018 \\
\hline \multirow[t]{12}{*}{ Sosyal } & Yerleştiren & Ayrıştıran & $-5.881^{*}$ & 2.759 & 0.037 \\
\hline & & Değiştiren & 1.167 & 2.810 & 0.679 \\
\hline & & Özümseyen & -5.325 & 2.791 & 0.061 \\
\hline & Ayriştıran & Yerleştiren & $5.881^{*}$ & 2.759 & 0.037 \\
\hline & & Değiştiren & $7.048^{*}$ & 1.915 & 0.000 \\
\hline & & Özümseyen & 0.556 & 1.887 & 0.769 \\
\hline & Değiştiren & Yerleştiren & -1.167 & 2.810 & 0.679 \\
\hline & & Ayrıştıran & $-7.048^{*}$ & 1.915 & 0.000 \\
\hline & & Özümseyen & $-6.491^{*}$ & 1.961 & 0.002 \\
\hline & Özümseyen & Yerleştiren & 5.325 & 2.791 & 0.061 \\
\hline & & Ayrıştıran & -0.556 & 1.887 & 0.769 \\
\hline & & Değiştiren & $6.491^{*}$ & 1.961 & 0.002 \\
\hline
\end{tabular}

Tablo 6'daki sonuçlar incelendiğinde "Mantıksal” zeka alanında "Yerleştirilen”, “Ayrıştıran”, “Özümseyen” ile "Değiştiren” öğrenme stilleri arasında istatistiksel olarak anlamlı farklılıklar olduğu tespit edilmiştir $(\mathrm{p}<0.05)$. "Değiştiren” öğrenme stiline sahip fen bilgisi öğretmen adaylarının mantıksal zeka alanından aldıkları puanların, diğer öğrenme stiline sahip fen bilgisi öğretmen adaylarına göre daha düşük olduğu görülmektedir. "Sosyal” zeka alanında "Ayrıştıran" ile "Yerleştiren", "Değiştiren” öğrenme stilleri arasında; “Özümseyen” ile "Değiştiren” öğrenme stilleri arasında istatistiksel olarak anlamlı farklılar 
belirlenmiştir $(\mathrm{p}<0.05)$. Ayrıştıran öğrenme stiline sahip fen bilgisi öğretmen adaylarının “Yerleştiren” ve "Değiştiren” öğrenme stiline sahip fen bilgisi öğretmen adaylarından "Sosyal” zeka alanında daha fazla puan aldıkları görülmektedir. Ayrıca “Özümseyen” öğrenme stiline sahip fen bilgisi öğretmen adaylarının "Değiştiren” öğrenme stiline sahip fen bilgisi öğretmen adaylarına göre "Sosyal” zeka alanından daha fazla puan aldıkları görülmektedir.

\section{Sonuçlar, Tartışma ve Öneriler}

Gerçekleştirilen bu çalışmada fen bilgisi öğretmen adaylarının çoklu zeka alanları ile öğrenme stilleri arasındaki ilişkiler incelenmiştir. Bu bölümde, inceleme sonucunda elde edilen bulguların sonuçları ve tartışmaları verilmiştir.

Çalışmaya göre fen bilgisi öğretmen adaylarının sekiz zeka alanına ilgilerinin olduğu söylenebilir. Fen bilgisi öğretmen adaylarının Çoklu Zeka Envanterindeki sekiz alana ait aldıkları puanların 33.64-38.36 arasında olduğu belirlenmiştir. Çoklu Zeka Envanterinden alınan puanlar 34-41 arasında ise, bireylerin gelişmiş seviyede olduğu söylenir (Özden, 2014). Fen bilgisi öğretmen adaylarının öğrenme biçimlerine bakıldığında, "Soyut Kavramsallaştırma (Düşünerek)" ve “Aktif Yaşantı (Yaparak)” öğrenme biçimlerinde diğer öğrenme biçimlerine göre daha yüksek bir puan ortalaması olduğu görülmektedir. Araştırmada elde edilen sonuçlar ile alanyazında yapılan araştırma sonuçların paralellik göstermektedir (Hamurcu, Günay ve Özyılmaz, 2002; Oral, 2001). Fen eğitiminin doğasında yaparak-yaşayarak öğrenme vardır (MEB, 2018). Bu durum fen bilimlerinde soyut ifadelerin fazla olması (kavram, teori, kuram ...) ve fen öğretiminde deney ve etkinliklerin ağırlıkta olmasıyla ilgilidir (Dagher, 1995; İnci, Zorlu ve Çil, 2009; Karamustafaoğlu, Karamustafaoğlu ve Yaman, 2005; MEB, 2018; NRC, 1996; Zorlu; 2016). Fen bilgisi öğretmenliği bölümünde öğrenim gören öğrencilerde fen bilimlerinin doğasında olan deney ve etkinliklerle soyut ifadeleri öğrenme isteği vardır (Atasoy 
2004; Erbaş, Şimşek, Çınar, 2005; Kaya, 2009; Lawson 1995; Looi, Hung, Bopry ve Koh, 2004; Pekmez, Johnson ve Gott, 2005; Zorlu, 2016). Bu doğrultuda araştırmaya katılan fen bilgisi öğretmen adaylarının öğrenme biçimlerinden "Soyut Kavramsallaştırma (Düşünerek)" ve “Aktif Yaşantı (Yaparak)” öğrenme biçimleri ön plana çıkmış olabilir.

Fen bilgisi öğretmen adaylarının ÖSE’nden elde edilen bulgulara göre sırasıyla “Ayrıştıran”, “Özümseyen”, “Değiştiren” ve "Yerleştiren” öğrenme stilleri olduğu belirlenmiştir. Alanyazın incelediğinde fen bilgisi öğretmen adaylarının en çok "Ayrıştıran” öğrenme stiline sahip oldukları tespit edilmiştir (Bahar, Özen ve Gülaçtı, 2009; Bahar ve Sülün, 2011; Cavas, 2010; Pehlivan, 2010). Bazı araştırmalarda fen bilgisi öğretmen adaylarının ikinci olarak “Özümseyen” öğrenme stilli olduğu görülmektedir (Bahar, Özen ve Gülaçtı, 2009; Bahar ve Sülün, 2011). Alanyazın incelediğinde araştırmada elde edilen sonuçlardan farklı sonuçlar elde eden araştırmaların olduğu görülmektedir. Kahyaoğlu (2011) araştırmasında ise fen bilgisi öğretmen adaylarının en çok “Özümseyen” öğrenme stiline sahip olduğunu ifade etmiştir. Gencel ve Köse (2011), fen bilgisi öğretmen adaylarının öğrenme stillerinde ikinci olarak "Yerleştiren” öğrenme stiline sahip oldukları ifade etmiştir.

Öğrenme biçimleri ile çoklu zeka alanları arasında ilişkiler incelediğinde "Aktif Yaşantı” öğrenme biçimi ile "Mantıksal” ve “Sosyal” zeka alanlarında pozitif yönde ve orta düzeyde doğrusal bir ilişki olduğu tespit edilmiştir. "Aktif Yaşantı" öğrenme biçiminin yaparak-yaşayarak öğrenmek, girişkenlik, grup çalışmasını sevmek, uygulamalı ödevler genel özelliklerinden bazılarıdır (Aşkar ve Akkoyunlu, 1993; Kolb, 1985; Kolb ve Kolb, 2005; Saban, 2005). Aktif Yaşantı” öğrenme biçimlerinin özelliklerden yararlanarak Fen bilgisi öğretmen adaylarının "Mantıksal” ve "Sosyal” zeka alanları geliştirmek için kullanılabilir. Ayrıca derslerde yaparak-yaşayarak öğrenmeyi sağlayan öğrenme model/yöntemleri tercih 
edilebilir. Örneğin işbirlikli öğrenme modelinin heterojen gruplar özelliği kullanılarak derslerde gruplar oluşturulup grup çalışmaları yapılabilir (Bayrakçeken, Doymuş ve Doğan, 2013). Ödevler verilirken uygulamalı ödevler tercih edilebilir. Örneğin fen bilimleri için proje ve performans ödevleri verilebilir. Fen eğitiminde proje ve performans ödevleri ile ilgili yapılan araştırmalarda öğretmen adaylarının olumlu tutumlar geliştirdikleri, konuları daha iyi öğrendikleri ve yaratıcılıklarının geliştiği görülmektedir (Aktamış ve Can, 2007).

"Mantıksal” zeka alanı ile "Somut Yaşantı" öğrenme biçimi ve "Sosyal” zeka alanı ile “Yansıtıcı Gözlem” öğrenme biçimleri arasında negatif ilişkiler belirlenmiştir. Bu bağlamda, fen bilgisi öğretmen adaylarının soyutlaştırma ve somutlaştırma arasında denge kurması gerektiği söylenebilir. Ayrıca "Yansıtıcı Öğrenme” öğrenme biçimine sahip fen bilgisi öğretmen adaylarının "Sosyal Zeka” alanlarının geliştirilmesi gerekmektedir. Öğretmen adayları, insanlar ile ilişkiler kurarak çevresini anlayıp buna yönelik eylemlerde bulunması ile sosyal zeka alanlarını geliştirebilir.

Fen bilgisi öğretmen adaylarının öğrenme stillerine göre çoklu zeka alanları incelediğinde "Mantıksal" ve "Sosyal” zeka alanlarında anlamlı farklılıklar olduğu tespit edilmiştir. "Değiştiren” öğrenme stiline sahip fen bilgisi öğretmen adaylarının diğer öğrenme stillerine sahip fen bilgisi öğretmen adaylarına göre "Mantıksal” zeka alanlarından aldıkları puanların daha düşük olduğu belirlenmiştir. "Mantıksal” zeka alanı ile "Değiştiren” öğrenme stilinin özelliklerinin birbirinden farklı yapılara sahip olduğu söylenebilir. "Mantıksal” zeka alanı soyut ilişkiler üzerine düşünmeleri içerirken, "Değiştiren” öğrenme stili somut değişimler üzerine öğrenmeyi içerir. "Değiştiren” öğrenme stiline sahip bireyler düşünüp yargıda bulunarak öğrenirken karşı bir eylemde bulunmazlar (Aşkar ve Akkoyunlu, 1993; Kolb, 1985; Kolb ve Kolb, 2005; Saban, 2005). "Mantıksal” zeka alanı ise, düşünmeden sonra eylemler 
yapma (hesaplama, sayısallaştırma) özelliklerini içermektedir. "Ayrıştıran” öğrenme stiline sahip fen bilgisi öğretmen adaylarının "Yerleștiren” ve "Değiştiren” öğrenme stillerine sahip fen bilgisi öğretmen adaylarına göre "Sosyal” zeka alanında daha yüksek puan aldıkları tespit edilmiştir. Bu sonuçtan hareketle, “Ayrıştıran” öğrenme stili ile "Sosyal” zeka alanının birbirine paralellik gösteren özelliklerinin olduğu söylenebilir. "Ayrıştıran” öğrenme stilinde problemi tanımlama ve çözme vardır. Bu stil, bir durumu anlayıp neden-sonuç ilişkisi üzerine yapılandırılmış öğrenme stilidir (Kolb, 1985; Kolb ve Kolb, 2005). "Sosyal” zeka alanın özelliklerinde ise bulunduğu ortamdaki kişileri anlama ve onlara yardımcı olma vardır (Gardner, 2011; Özden, 2014). Ayrıca bu çalışmada, “Özümseyen” öğrenme stiline sahip fen bilgisi öğretmen adaylarının “Değiştiren” öğrenme stiline sahip fen bilgisi öğretmen adaylarına göre "Sosyal” zeka alanından aldıkları puanların yüksek olduğu belirlenmiştir. "Değiştiren" öğrenme stiline sahip bireyler, “Özümseyen” öğrenme stiline sahip bireylere göre insanlara duyarlı olmada daha zayıftırlar (Kolb, 1985; Kolb ve Kolb, 2005). “Sosyal” zeka alanında ise çevresinde var olan kişilere duyarlı olup onları anlama ve yardımcı olma özellikleri vardır (Başaran, 2004; Garner, 2000, 2003; Özden, 2014).

Eğitimde kaliteyi artırmak adına öğretmen adaylarının özelliklerinin tespit edilmesi önemlidir. Bu araştırmada çoklu zeka alanları ile öğrenme biçimleri arasında negatif ve pozitif yönlü ilişkiler olduğu belirlenmiştir. Negatif yönlü ilişkilerde fen bilgisi öğretmen adaylarının sosyal zeka alanlarının geliştirilmesi ile fen bilgisi öğretmen adaylarının daha etkili ve kalıcı şekilde öğrenmelerine olanak sağlanacağı düşünülmektedir. Sosyal ilgi alanlarının geliştirilmesi, teknolojinin getirdiği olumsuz durumları ortadan kaldırmakla mümkün olabilir. Sınıf içi uygulamalarla, grup çalışmalarıyla, proje odaklı ödevlerle ve teknolojinin olumsuz durumlarının ortadan kaldırılmasına yardımeı olan uygulamalarla sosyal ilgi alanının gelişmesine katkılar sağlanacağı düşünülebilir. Gerçekleştirilen bu araştırma göstermektedir 
ki, çoklu zeka alanları ile öğrenme stilleri ilişkilidir ve bu ilişkilerden yola çıkarak öğrenme süreci daha iyi planlanabilir. Bu bağlamda ileride, çoklu zeka alanları kullanılarak fen bilgisi öğretmen adaylarının öğrenme biçim ve stillerindeki eksik kısımlar tamamlanarak yeterliklerinin artırılmasına yönelik uygulamalar yapılabilir.

\section{Makalenin Bilimdeki Konumu (Yeri)}

\section{Fen Bilgisi Eğitimi ABD}

\section{Makalenin Bilimdeki Özgünlüğü}

Kaliteli fen eğitiminin olabilmesi için fen bilgisi öğretmen adaylarının eğitimine önem verilmelidir. Fen bilgisi öğretmen adaylarının çoklu zeka alanları ile öğrenme biçim ve stillerindeki ilişkilerin incelenmesi ve aralarındaki ilişkilerin bilinmesi ile öğrenme biçim ve stillerinin doğuştan gelen karakteristik bir özellik olduğu ve değişmesinin zor olacağ düşünüldüğünde öğrenme biçim ve stillerini geliştirmek için çoklu zeka alanlarını dikkate alan uygulamalarda kullanılabilirliği ve çoklu zeka alanlarını geliştirmek için öğrencilerin öğrenme biçim ve stillerine göre uygulamaların yapılabilirliği düşünüldüğünde oldukça önem arz etmektedir. Fen bilgisi öğretmen adaylarının ilgi alanlarına ve öğrenme biçim/stillerine yönelik eksiklerin giderilmesi açısından çoklu zeka alanları ile öğrenme biçim ve stilleri arasındaki ilişskilerin bilinmesi ve ilişkilere göre uygulamaların yapılması bu alandaki ihtiyaçların giderilmesinde yardımcı olabilir. Literatürde fen bilgisi öğretmen adaylarının çoklu zeka alanları ile öğrenme biçim ve stilleri arasındaki ilişkileri inceleyen araştırmaya rastlanmamıştır. 


\section{Kaynakça}

Aktamış, H. \& Can, B. T. (2007). Fen öğretmen adaylarının yaratıcılık inançları. e-Journal of New World Sciences Academy Social Sciences, 2(4), 484-499.

Aşkar, P. \& Akkoyunlu, B. (1993). Kolb öğrenme stili envanteri. Science and Education, 87, $37-47$.

Atasoy, B. (2004). Fen öğrenimi ve ögrretimi. Ankara: Asil.

Aygül, İ. (2015). Tunceli Üniversitesi Meslek Yüksekokulu öğrencilerinin çoklu zeka alanları ile öğrenme stillerinin incelenmesi. (Yayımlanmamış yüksek lisans tezi) Cumhuriyet Üniversitesi, Eğitim Bilimleri Enstitüsü, Sivas.

Bahar, H. H. \& Sülün, A. (2011). The learning styles of prospective science teachers, the correlation between learning styles and gender and academic achievement by learning styles. Kastamonu Education Journal, 19(2), 379-386.

Bahar, H. H., Özen, Y., \& Gülaçtı, F. (2009). Eğitim fakültesi öğrencilerinin cinsiyet ve branşlara göre akademik başarı durumları ile öğrenme stillerinin incelenmesi. Ankara Üniversitesi Eğitim Bilimleri Fakültesi Dergisi, 42(1), 69-86.

Başaran, I. (2004). Etkili öğrenme ve çoklu zeka kuramı: Bir inceleme. Ege Eğitim Dergisi, 5, 7-15.

Bayrakçeken, S., Doymuş, K., \& Doğan, A. (2013). İşbirlikli öğrenme modeli ve uygulaması (1. Bask1). Ankara: Pegem Akademi.

Boydak, A. (2008). Öğrenme stilleri (12.basım). İstanbul: Beyaz.

Büyüköztürk, Ş. (2010). Sosyal bilimler için veri analizi el kitabi (11. Baskı). Ankara: Pegem Akademi. 
Çalışandemir, F. (2010). Anasınıfi çocuklarının çoklu zekâ alanlarının gelişimine deney yöntemiyle verilen eğitimin etkisinin incelenmesi. (Yayımlanmamış doktora tezi) Hacettepe Üniversitesi, Sağlık Bilimleri Enstitüsü, Ankara.

Cavas, B. (2010). A study on pre-service science, class and mathematics teachers' learning styles in turkey. Science Education International, 21(1), 47-61.

Chambel, T. \& Guimarães, N. (2005). Learning styles and multiple intelligences. İçinde Encyclopedia of Distance Learning (ss. 1237-1247). IGI Global.

Curry, L. (1990). A critique of the research on learning styles. Educational Leadership, 49, 5056.

Dagher, Z. R. (1995). Analysis of analogies used by science teachers, Journal of Research in Science Teaching, 32(3), 259-270.

Demir, R. \& Aybek, B. (2014). An examination of learning styles and multiple intelligences fields of ninth grade students. International Journal of Curriculum and Instructional Studies, 2(4), 27-40.

Denig, S. (2004). Multiple intelligences and learning styles: Two complementary dimensions. Teacher College, 106(1), 96-111.

Erbaş, S., Şimşek, N., \& Çınar, Y. (2005). Fen bilgisi laboratuvarı ve uygulamaları. Ankara: Nobel.

Gardner, H. (1993). Multiple intelligences-The theory in practise. New York: Basic Boks.

Gardner, H. (1994). The creators’ patterns. Boden, M. A. (Ed.). Dimensions of creativity. MIT Press.

Gardner, H. (2004). Audiences for the theory of multiple intelligences. The Teachers College Record, 106(1), 212-220.

Gardner, H. (2006). Çoklu zeka ve yeni ufuklar. (A. Hekimoğlu Gül, Çev.). İstanbul: Optimist. 
Gardner, H. (2010). Çoklu zekâ kuramı: Zihin çerçeveleri. (E. Kılıç, Çev.). İstanbul: Alfa.

Gardner, H. (2011). Frames of mind: The theory of multiple intelligences. Basic books.

Garner, I. (2000). Problems and inconsistencies with Kolb’s learning styles. Educational Psychology, 20, 341-349.

Gencel, İ. E. \& Köse, A. (2011). Relationship between the prospective science teachers' learning styles, learning and study strategies and self-efficacy beliefs in science teaching. Journal of Theory and Practice in Education, 7(2), 311-333.

Gürçay, D. \& Eryılmaz, A. (2002). Lise 1. sınıf öğrencilerinin çoklu zeka alanlarının tespiti ve fizik eğitimi üzerine etkisi. V. Ulusal Fen Bilimleri ve Matematik Eğitimi Kongresi. Ankara.

Gürel, E. \& Tat. M. (2010). Çoklu zekâ kuramı: Tekli zekâ anlayışından çoklu zeka yaklaşımına. The Journal of International Social Research, 3(11), 336-356.

Hamurcu, H., Günay, Y., \& Özyılmaz, G. (2002). Buca eğitim fakültesi fen bilgisi ve sınıf öğretmenliği bölümü öğrencilerinin çoklu zekâ kuramına dayalı profilleri, V. Ulusal Fen Bilimleri ve Matematik Ĕgitimi Kongresi, Ankara.

Hunt, D. E. (1987). Beginning with ourselves in practice, theory and human affairs. Cambridge MA: Brookline Books.

İnci, N., Zorlu, Y., \& Çil, E. (2009). İlköğretim 6. sınıf öğrencilerinin “yer kabuğu nelerden oluşur?” ünitesindeki kavramlarının anlaşılma düzeyleri ile kavram yanılgılarının belirlenmesi ve bazı değişkenler açısından incelenmesi, e-Journal of New World Sciences Academy (NWSA), 4(4), 1160-1170.

Kahyaoğlu, M. (2011). The views of elementary teachers on using new technologies in science and technology teaching. Journal of Educational Sciences Research, 1(2), 68-82.

Karamustafaoğlu, S., Karamustafaoğlu, O., \& Yaman, S. (2005). Fen ve Teknoloji Öğretimi, Mustafa Aydoğdu ve Teoman Kesercioğlu (Ed.), Ankara: Anı Yayıncılık. 
Karasar, N, (2016). Bilimsel araştırma yöntemi. Ankara: Nobel.

Karatekin, K., Sönmez, Ö. F., \& Kuş, Z. (2010). Çoklu zekâ kuramına göre hazırlanmış öğretim etkinliklerinin uygulanması ile ilgili öğretmenlerin düşünceleri ve karşılaşılan sorunlar. Türkiye Sosyal Araştırmalar Dergisi, 14(2), 139-154.

Kaya, N. (2009). Birlikte ögrenme gruplarında pratik deney ve materyal tasarımlarl ile biyoteknoloji öğretiminin başarı ve tutum üzerine etkileri. Yayımlanmamış Yüksek Lisans Tezi, Muğla Üniversitesi Fen Bilimleri Enstitüsü, Muğla.

Keefe, J. W. (Ed.). (1982). Student learning styles and brain behavior: Programs, instrumentation, research. Reston, VA: National Associationof Secondary School Principals.

Klein, P. D. (2003). Rethinking the multiplicity of cognitive resources and curricular representations: Alternatives to "learning styles" and "multiple intelligences”. Journal of Curriculum Studies, 35, 45-81.

Kolb, D. A. (1984). Experiential learning: Experiences as the source of learning and development. Englewood Cliffs, N.J. :Prentice-Hall.

Kolb, D. A. (1985). Learning style inventory: Self scoring inventory and interpretation booklet. Boston: McBer and Company.

Kolb, A. Y. \& Kolb, D. A. (2005). Learning styles and learning spaces: Enhancing experiential learning in higher education. Academy of Management Learning and Education, 4(2), 193212.

Lawson, A. E. (1995). Science teaching and the development of thinking. Wadsworth publishing company. 
Looi, C. K., Hung, D., Bopry, J., \& Koh, T. S. (2004). Singapore’s learning sciences lab: seeking transformations in ICT-enabled pedagogy. Educational Technology Research \& Devolopment, 52(4), 91-115.

MEB (Milli Eğitim Bakanlı̆̆ı) (2018). Fen bilimleri dersi ögretim programı (ilkokul ve ortaokul 3, 4, 5, 6, 7 ve 8. sinıflar) ögretim programı. Ankara: Devlet Kitapları Basım Evi.

Morgan, C. (1981). Psikolojiye giriş. Ankara: Hacettepe Üniversitesi.

NRC (National Committee on Science Education Standards and Assessment) (1996). National Science Education Standards. Washington, DC: National Academy Press.

Oral, B. (2001). Branşlarına göre üniversite öğrencilerinin zekâ alanlarının incelenmesi. Eğitim ve Bilim Dergisi, 122(26), 19-31.

Özden, Y. (2014). Öğrenme ve ögretme. Ankara: PegemA.

Özdoğru-Şenel, S. (2016). Çoklu zeka kuramına göre düzenlenen etkinliklerin 7. sınıf lşık ünitesinin ögrrenilmesi ve öğrenmenin kalıcllı̆̆ üzerine etkisi. (Yayımlanmamış yüksek lisans tezi) Gazi Üniversitesi, Eğitim Bilimleri Enstitüsü, Ankara.

Pallant, J. (2003). SPSS survival manual. Buckingham, PA: Open University Press.

Pehlivan, K. B. (2010). Öğretmen adaylarının öğrenme stilleri ve öğretmenlik mesleğine yönelik tutumları üzerine bir çalışma. İlköğretim Online, 9(2), 749-763.

Pekmez, E. S., Johnson, P., \& Gott, R. (2005). Teacher's understanding of the nature and purposes of practical work. Research in Science \& Technological Education, 23(1), 3-23.

Saban, A. (2005). Çoklu Zekâ Teorisi ve Eğitim. Ankara: Nobel.

Silver, H. F., Strong, R. W., \& Perini, M. J. (2000). So each may learn: Integrated learning styles and multiple intelligences. Alexandria, VA: Association for Supervision and Curriculum Development.

Taşkın, E. (2017). Çoklu Zeka Kuramındaki görsel zekanın Sosyal Bilgiler 7.sınıf 'Zaman İçinde Bilim' ünitesine uygulanmasının ögretime etkililiği (YBO örneği). (Yayımlanmamış yüksek lisans tezi) Marmara Üniversitesi, Eğitim Bilimleri Enstitüsü, İstanbul.

URL-1. http://www.atauni.edu.tr/\#sayfa=ibm-spss-statistics-20 
Yağcı, Z. (2006). Çoklu zeka kuramının ilköğretim altıncı sınıffen bilgisi öğretiminde öğrenci başarısına etkisi. (Yayımlanmamış yüksek lisans tezi) Balıkesir Üniversitesi, Fen Bilimleri Enstitüsü, İlköğretim Anabilim Dalı, Balıkesir.

Zull, J. E. (2002). The art of changing the brain: Enriching teaching by exploring the biology of learning. Sterling, VA: Stylus.

Zorlu, Y. (2016). Ortaokul fen ve teknoloji dersinde işbirlikli öğrenme modeli ve modellemeye dayalı öğretim yöntemine dayalı etkinliklerin öğrencilerin öğrenmeleri üzerindeki etkileri. Yayınlanmamış doktora tezi. Atatürk Üniversitesi Eğitim Bilimler Enstitüsü, Erzurum.

\section{Summary}

\section{Problem Statement}

It is thought that there is a similarity between Gardner's eight intelligence areas and Kolb’s four learning orientations and styles but they are not completely the same (Zull, 2002). Denig (2004) and Gardner (2003) stated that multiple intelligence areas and learning orientations and styles are not the same thing that is they are different from each other. Learning orientations and styles are inborn characteristic features and it is rather difficult to alter them but the skills belonging to one of the multiple intelligence areas are more and they can be altered in time (Boydak, 2008; Gardner, 2003). Gardner (2003) stated that the relationship between learning orientations and styles with multiple intelligences should be examined. When the literature is reviewed, it is seen that there are so few studies dealing with the relationship between learning orientations and styles with multiple intelligences (Aygül, 2015; Chambel and Guimarães, 2005; Demir and Aybek, 2014; Klein, 2003; Silver, Strong and Perini, 2000). Learning orientations and styles are innate characteristics, and it is very difficult to change these characteristics. However, individual skills in a particular intelligence area can be higher than skills in another intelligence area, and this situation might change over time. Investigating 
and determining the relationship between learning orientations and styles with multiple intelligence areas are of critical importance for the following reasons:

1. This relationship plays a role in the implementations on multiple intelligence areas to improve learning orientations and styles, considering that learning orientations and styles are innate characteristics and it is very difficult to change these characteristics.

2. Implementations should be made according to students' learning orientations and styles to improve multiple intelligence areas.

One of the aims of education is to meet the needs of the individual and society. Determining the relationship between multiple intelligence areas with learning orientations and styles to help individuals overcome any deficiencies in their field of interests and/or their learning orientations and styles, and conducting implementations according to this relationship would serve to meet the needs of the individual and society.

Purpose of the Study: Moreover, no undergraduate level study is found in the field of sciences in literature. In this direction, it was aimed in the study to examine the relationships among the multiple intelligence areas with the learning orientations and styles of preservice elementary science teachers. Is there a relationship between the sophomore pre-service science teachers’ multiple intelligence areas with their learning orientations and styles?

\section{Method}

Correlational design was used in the research. The research pattern aiming at determining the existence and/or degree of covariance between two or more variables is the relational research. The correlational analysis in the correlational survey pattern is the correlation type relationships or relationships obtained by comparisons (Karasar, 2016). By using the Correlational desing, it was aimed to examine the relationships between the multiple intelligence areas with learning orientations and styles styles of preservice elementary science 
teachers. The participants of the study were determined using the purposeful sampling technique. The class level determined to be the beginner level, in terms of what the science teaching profession requires, was set as the purpose for the participants' selection. In line with this purpose, the sophomore pre-service science teachers were selected among the students from the science education department. 64 preservice elementary science teachers who are sophomores in the faculty of education of a state university participated in the research. In the study, Multiple Intelligences Inventory (MII) and Learning Styles Inventory (ESE) were used as data collection tools. One-way analysis of variance (ANOVA) and simple correlation analysis which are predictive statistical analyses were made.

\section{Findings}

It was determined that preservice elementary science teachers generally got points between 33.64 and 38.36 in all intelligence areas. It can be said that all intelligence areas of preservice elementary science teachers are at developed level. it is seen that the point average of “Abstract Conceptualization (Thinking)” and “Active Experimentation (Doing)” learning orientations is higher than the other learning orientations. It was determined that there is a negative and significant relationship between the "Logical" intelligence area and "Concrete Experience" learning orientation, and "Interpersonal" intelligence area and "Reflective Observation” learning orientation of preservice elementary science teachers (Logical Intelligence with Concrete Experience: Pearson's r=-0.280; $\mathrm{p}<0.05$. Interpersonal Intelligence with Reflective Observation: Pearson's $\mathrm{r}=-0.262$; $\mathrm{p}<0.05$ ). It was determined that there is a positive and significant relationship between the "Logical" intelligence area and "Active Experimentation" learning orientation and "Interpersonal" intelligence area and "Active Experimentation” learning orientation of preservice elementary science teachers (Logical Intelligence with Active Experimentation: Pearson's $\mathrm{r}=0.313 ; \mathrm{p}<0.05$. Interpersonal 
Intelligence with Active Experimentation: Pearson's $\mathrm{r}=0.504 ; \mathrm{p}<0.05$ ). It is seen that approximately $9.4 \%$ of preservice elementary science teachers possess the "Accommodating" learning style while approximately 32.8\% possess "Diverging" learning style. it was determined that there are statistically significant differences in "Logical" and "Interpersonal" intelligence areas of preservice elementary science teachers with respect to learning styles [Logical Intelligence Area: $\mathrm{F}_{(3,63)}=4.105 ; \mathrm{p}=0.010$. Interpersonal Intelligence Area: $\left.F_{(3,63)}=6.017 ; p=0.001\right]$. Statistically significant differences were determined between the "Accommodating", "Diverging", "Assimilating" and "Converging" learning styles in "Logical" intelligence area $(\mathrm{p}<0.05)$. It is seen that the points that preservice elementary science teachers who possess diverging learning style got in logical intelligence area are lower than the preservice elementary science teachers who possess other learning styles. In the field of "Interpersonal" intelligence area, it was determined that there statistically significant differences between the "Diverging", and "Accommodating" and "Converging" learning styles and between the "Assimilating" and "Converging" learning styles $(\mathrm{p}<0.05)$.

\section{Discussion, Conclusion and Suggestions}

When the relationships between multiple intelligence areas with learning orientations are reviewed, a positive and medium level linear relationship was found between the "Active Experimentation" learning orientation and "Logical" and "Interpersonal" intelligence area. It is seen that there are negative relationships between "Logical" intelligence area and "Concrete Experience" learning orientation and between "Interpersonal" intelligence area and "Reflective Observation" learning orientation. In this context, it can be said that preservice elementary science teachers should establish a balance between abstracting and concretization. Moreover the preservice elementary science teachers who possess reflective learning orientations should develop their social intelligence area. Preservice teacher can develop their social intelligence 
area by establishing relationships with others, understanding their environment and acting accordingly. When the multiple intelligence areas are examined with respect to learning styles of preservice elementary science teachers, it was determined that there are significant differences in "Logical" and "Interpersonal" intelligence areas. It was determined that preservice elementary science teachers who possess "Converging" learning style got lower points in "Logical" intelligence area than preservice elementary science teachers who possess other learning styles. It can be said that the features of "Logical" intelligence area and converging learning style have different structures. While "Logical” intelligence area involves thinking about abstract relationships, “Converging” learning style involves learning about concrete changes. Individuals who possess “Converging” learning style learn by thinking and making judgement and don't do opposite acts (Aşkar and Akkoyunlu, 1993; Saban, 2005). "Logical” intelligence area, on the other hand, involves acting after thinking (calculating, digitizing). It was determined that preservice elementary science teachers who possess “Diverging” learning style got higher points in "Social” intelligence area than preservice elementary science teachers who possess “Accommodating” and "Cconverging” learning styles. From these results forth, it can be said that "Diverging” learning style and "Interpersonal” intelligence area have features that show parallelism with each other. “Diverging” learning style is based on problem identification and solution. This style is the learning style structured on understanding a situation and using cause and effect relationship. "Interpersonal” intelligence area, on the other hand, is based on understanding the individuals in the environment and helping them (Gardner, 2011; Özden, 2014). In this study it is also determined that preservice elementary science teachers who possess “Assimilating” learning style got higher points in "Social” intelligence area than preservice elementary science teachers who possess “Converging” learning style. Individuals who possess “Converging” learning 
YYÜ Eğitim Fakültesi Dergisi (YYU Journal of Education Faculty), 2019; 16(1):49-78, http://efdergi.yyu.edu.tr

style are weaker in being sensitive to people than the individuals who possess “Assimilating” learning style. "Social” intelligence area is sensitive to others around, understands and helps them (Başaran, 2004; Garner, 2000, 2003; Özden, 2014). It is important to determine the features of preservice teachers to increase the quality of education. This research confirms that multiple intelligence areas and learning orientations/styles are interrelated and these relationships would help planning the learning process better. In this context the loose ends in the learning orientation and styles of preservice elementary science teachers would be completed by using multiple intelligence areas and applications to increase their competence would be performed.

Keywords: Elementary Science Education, Learning Style, Multiple Intelligence. Teacher Education 